\title{
Correlation Between Specific Component of Mental Health and Psychological Well-Being of Filipino Older People
}

\author{
Perry Paul J. Espinosa \\ Assistant Professor, Department of Nursing \\ Woosong College, Daejeon, Republic of Korea \\ paulespinosa721@gmail.com
}

\begin{abstract}
This is a descriptive-correlational study, conducted in February 2014, which aimed to determine the specific component of mental health and psychological well-being of Filipino older people. The respondents of the study were the 264 older people in eight identified areas in the Province of Iloilo, Philippines. Mental health has an effect on the psychological well-being of the older people. Those older people who have good mental health are more likely to have a good sense of autonomous well-being, greater personal growth and higher sense of meaning in life, better control of the environment, more confident, and positive attitude toward self. Furthermore, the more they are involved with activities, the more likely they are satisfied with their lives. On the other hand, however, good mental health does not essentially equate better relations with others. Recommendations include strategies to improve promotion of mental health and social relations of the older people.
\end{abstract}

Keywords: Mental health, psychological well-being, older people, aging population, depression, autonomy

\section{Background of the Study}

In the Philippines, the number of older people is aging rapidly. The current population of Filipino older people is estimated at seven million, comprising nearly seven percent of the total population. In the foreseeable future, the percentage of seniors vis-a-vis the total population shall escalate to 10 percent and beyond (Romulo, 2015) [1].

Mental health is defined as a state of well-being in which every individual realizes his or her own potential, can cope with the normal stresses of life, can work productively and fruitfully, and is able to make a contribution to her or his community (World Health Organization, 2014) [2]. Thus, mental health is essential to overall health and well-being (World Health Organization, 2016) [3].

The importance of mental health to aging is that one cannot age well without good mental health (Friedman, First, \& Williams, 2010) [4]. While most of the older people have good mental health, getting older are at risk of developing mental disorders (World Health Organization, 2014) [5]. As people age, the mental health needs also increases. There is a great body of evidence of a rise in morbidity, mortality, hospitalization, and loss of functional status related to common mental disorders among the aged (Parkar, 2015) [6]. Older people face special mental health challenges which need to be recognized (World Health Organization, 2016) [3].

Well-being is a multi-faceted concept (Seifert, 2011) [7]. It is considered as important aspect of life of the older people, as an indicator of psychological adjustment (Ordonez, Lima-Silva, and Cachioni, 2011) [8] and as an adaptation of life events (Luhman, Hofmann, Eid, \& Lucas, 2012) [9]. Ryff (1995) [10] has conceptualized the psychological well-being as consisting of six dimensions such as autonomy, environmental mastery, personal growth, positive relations with others, purpose in life, and self-acceptance. 
Mental health and well-being are as important in older age as at any other time of life (World Health Organization, 2016) [3]. Although, these aspects have been extensively studied, yet, there is paucity of research in this area. Locally, no correlational studies have been found in the context of mental health and psychological well-being among older people.

This study determined the specific component of mental health and psychological wellbeing of Filipino older people specifically in the Province of Iloilo, Philippines.

\section{Significance of the Study}

The results of the study may be significant to the following:

Department of Health, as the primary agency who oversees the health of the Filipino citizenry not only physical but also to include mental health and psychological well-being of older people.

Mental Health Professionals, as the front liners who performs early detection and prevention addressing the special needs of older people.

Policy Makers, as the political arm who drafts rules and by-laws that benefit the growing needs and older population of the society.

Colleges of Nursing, as the sector that develop trainings, modules, and curricula integrating the theoretical and conceptual foundations in the education of nurses.

Public Health Nurses, as the implementers of health-related activities and programs directly in contact with the older people whether in the rural or urban areas.

Non-Governmental Organizations, as the partners of the government in the implementation and creation of initiatives that focus on the specific problem of the clientele.

Older People, as the recipients of this investigation, thus improving quality of life among them.

Family Members, as the support system of the Older People, they also need support, care, and direction as they live with them.

\section{Methodology}

\section{Research Design}

This is a descriptive-correlational research that utilized one-shot survey design. The descriptive study describes systematically, factually, and accurately the facts and characteristics of the respondents under study. The relational analysis measures the extent or magnitude of association between two variables (David, 2005) [11].

\section{The Respondents}

Two-hundred sixty-four older people served as respondents of the study. This number represents twenty percent of the 1,308 older people in both urban and rural barangays in the Province of Iloilo, Philippines. The older people were classified based on their chronological age, namely; young old (60-70 years old), middle old (71-80 years old), and old old (81 years and older).

\section{Research Instruments}

To measure the mental health of the older people, the Scaled General Health Questionnaire (GHQ-28) by David Goldberg and Institute of Psychiatry (1981, cited in 
Goldberg and Williams, 2006) [12] was used. The Scaled General Health Questionnaire is a 28-item questionnaire, which is divided into four sub-scales, namely: somatic symptoms, anxiety and insomnia, social dysfunction, and depression. Furthermore, the Scale of Psychological Well-Being (Ryff, 1995) [10] is an instrument that specifically focuses on measuring multiple facets of psychological well-being, which was used to measure the psychological well-being of the older people. The dimensions were autonomy, environmental mastery, personal growth, positive relations with others, purpose in life, and self-acceptance (C. Ryff, personal communication, February 2, 2013).

The questionnaires were translated into local dialect and found to have high internal consistency coefficient values (0.82 to 0.93 for the Scaled General Health Questionnaire and 0.86 to 0.93 for the Scale of Psychological Well-Being) and were granted the permission to use.

\section{Ethical Considerations}

Consent from the respondents was secured prior to data gathering. The consent indicated that the respondents' confidentiality and privacy were highly maintained, and that the results should be used for research purposes only.

\section{Statistical Analysis}

The Gamma test was used in determining the relationship between specific component of mental health and psychological well-being. The level of significance was set at 0.05 .

\section{Results and Discussions}

\section{Specific Component of Mental Health and Psychological Well-being in terms of Autonomy of the Older People}

The results of the correlational analysis between the specific component of mental health of the older people such as somatic complaints, anxiety and insomnia, social dysfunction, and depression and their psychological well-being in terms of autonomy, environmental mastery, personal growth, positive relation with others, purpose in life, and self-acceptance are presented in Table 1 to 7, utilizing the statistical treatment of Gamma coefficient.

\section{Table 1. Correlation between Specific Component of Mental Health and Autonomy}

\begin{tabular}{|c|l|l|l|}
\hline \multirow{2}{*}{$\begin{array}{l}\text { Specific Component of } \\
\text { Mental Health }\end{array}$} & \multicolumn{3}{|c|}{ Autonomy } \\
\hline Somatic & Gamma & p-value & Decision Rule \\
\hline Anxiety and Insomnia & 0.267 & 0.030 & Significant \\
\hline Social Dysfunction & 0.196 & 0.093 & Not Significant \\
\hline Depression & 0.298 & 0.025 & Significant \\
\hline
\end{tabular}

The statistical data between mental health and autonomy shows a significant relationship between somatic complaints and autonomy. The Gamma coefficient of 0.267 $(\mathrm{p}=0.030)$ indicates a positive and significant at .05 level. This finding allows for the rejection of the null hypothesis that somatic complaints and autonomy are not significantly correlated. The positive correlation between two variables implies that the healthier mental condition they have, the better their autonomy. Good mental health is more likely an indicator of a good sense of autonomous well-being. The result is supported by the findings of Taloyan, Sundquist, and Al-Windi (2008) [13] that somatic pains and gastrointestinal complaints are significantly and independently related to poor 
psychological well-being. On the contrary, the study of Roothman, Kirsten, and Wissing (2003) [14], reported that somatic symptoms are not significantly correlated to psychological well-being.

Anxiety and insomnia are not significantly correlated with autonomy as evidenced by a Gamma value of $0.196(\mathrm{p}=0.093)$. This indicates that those respondents who have no difficulty in sleeping and are not nervous are more likely develop either high or low sense of autonomy. The relationship of anxiety and insomnia to illness is well known, however, the result of the study is an indication that these conditions have no influence on their state of being independent. On the other hand, Hamilton, et al., (2007) [15] reported that symptoms of insomnia were found to have a significant relationship with both psychological and subjective well-being but a stronger relationship to subjective wellbeing. These data suggest that insomnia symptoms have a stronger relationship to enjoying life than to the perception that one has a meaningful life. In addition, Mousavi et al., (2012) [16] reported that insomnia was significantly related to autonomy.

In terms of social dysfunction and autonomy, Gamma test reveal that there is a significant relationship existed between two variables $(\mathrm{Gamma}=0.298 ; \mathrm{p}=0.025)$. The study rejects the null hypothesis that there is no significant relationship between social dysfunction and autonomy. This implies that good social function is a predictor of a better autonomy. Older people who are satisfied and capable of making decisions are more likely to be independent and self-determined. They may not afraid to voice their opinions and their decisions may not be usually influenced by what everyone else is doing.

Depression and autonomy are not significantly correlated at .05 level as evidenced by the Gamma value of $0.292(\mathrm{p}=0.084)$. This means that mental health in terms of depression does not depend on the respondents' autonomy. This signifies that thinking life as worthless and is not worth living has nothing to do with their ability to make important decisions. In contrary, the findings of Dhara and Jogsan (2013) [17] and Balkir, Arens, and Barnow (2013) [18] revealed that depression and psychological wellbeing is significantly correlated. Beekman et al., (2002) [19] reported that depressive symptoms have considerable impact on the well-being and disability of older people.

\section{Specific Component of Mental Health and Psychological Well-being in terms of Environmental Mastery of the Older People}

The statistical analysis between mental health and environmental mastery illustrate that there is no significant correlation between somatic complaints and environmental mastery (Gamma $=0.180 ; \mathrm{p}=0.098$ ). The null hypothesis, therefore, somatic complaints is not correlated with environmental mastery is accepted. This means that somatic complaints have no influence on the sense of mastery and competence in managing the environment of the older people.

Table 2. Correlation between Specific Component of Mental Health and Environmental Mastery

\begin{tabular}{|l|l|l|l|}
\hline \multirow{2}{*}{$\begin{array}{l}\text { Specific Component of } \\
\text { Mental Health }\end{array}$} & \multicolumn{3}{|c|}{ Environmental Mastery } \\
\hline Somatic & Gamma & p-value & Decision Rule \\
\hline Anxiety and Insomnia & 0.189 & 0.098 & Not Significant \\
\hline Social Dysfunction & 0.399 & 0.000 & Significant \\
\hline Depression & 0.275 & 0.028 & Significant \\
\hline
\end{tabular}

As to anxiety and insomnia and environmental mastery, the result show that a positive significant relationship between these variables $(\mathrm{Gamma}=0.399 ; \mathrm{p}=0.000)$. This indicates that those respondents who are not scared, less anxious, and not insomniacs had good 
psychological well-being in terms of environmental mastery. Good mental health leads to better competence in managing the many responsibilities of daily life.

The above mentioned finding is supported by Garcia, Al-Nima, and Kjell (2014) [20] in which good mental condition in terms of anxiety and insomnia influence human ability to adapt to changing environments. Significant relationship was found between social dysfunction and environmental mastery as evidenced by Gamma value of 0.275 $(\mathrm{p}=0.028)$. This implies that good mental influence environmental mastery. Thus, those older people who are keeping themselves busy, occupied, and doing things well are more likely to have better sense of control of their environment.

As to mental condition in terms of depression and environmental mastery, statistical result show moderate positive significant correlation (Gamma $=0.570 ; \mathrm{p}=0.000$ ). This implies that older people with no signs and symptoms of depression are more likely to have high environmental mastery. Thus, they may make use of surrounding opportunities. Similarly, Knight et al. (2011) [21] concluded that environmental mastery may be one of the more important factors affecting the mental health of older adults living in residential care and that strategies for increasing the residents' environmental mastery are important to their psychological well-being.

Indeed, the findings is in consonance with the Activity Theory by Havighurst (cited in Toughy and Jett, 2010) [22] which states that psychologically and physically healthiest response to old age is to maintain the greatest possible level of activity and involvement in the greatest possible number of roles. Thus, remaining to be active and engaged within the environment is pivotal to satisfaction in old age. Life satisfaction is directly related to the activities carried by the older people because involvement in such activity facilitates well-being and improved general health. This means that the more they are involved with activities, the more likely they are satisfied with their lives.

\section{Specific Component of Mental Health and Psychological Well-being in Terms of Personal Growth of the Older People}

The statistical data between mental health and personal growth reveal significant relationship between somatic complaints and personal growth (Gamma $=0.450 ; p=0.000)$. This means that somatic complaints influenced personal growth, in which, those older people who feel perfectly well and in good health are more likely to see self as growing and expanding. Thus, good condition in terms of somatic complaints is more likely to have better psychological well-being.

\section{Table 3. Correlation between Specific Component of Mental Health and Personal Growth}

\begin{tabular}{|l|l|l|l|}
\hline \multirow{2}{*}{$\begin{array}{l}\text { Specific Component of } \\
\text { Mental Health }\end{array}$} & \multicolumn{3}{|c|}{ Personal Growth } \\
\hline Somatic & Gamma & p-value & Decision Rule \\
\hline Anxiety and Insomnia & 0.450 & 0.000 & Significant \\
\hline Social Dysfunction & 0.436 & 0.001 & Significant \\
\hline Depression & 0.637 & 0.000 & Significant \\
\hline
\end{tabular}

Statistical analysis show that there is significant correlation between anxiety and insomnia and personal growth $(\mathrm{Gamma}=0.436 ; \mathrm{p}=0.001)$. This finding allows for the rejection of the null hypothesis that mental health in terms of anxiety and insomnia and personal growth are not significantly correlated. This means that those respondents who do not have difficulty sleeping and are not edgy and bad-tempered are more likely to have better well-being.

As to social dysfunction and personal growth, significant relationship existed between two variables $(\mathrm{Gamma}=0.637 ; \mathrm{p}=0.000)$. This means that social function affects personal 
growth. This implied that older people who are satisfied in carrying task and doing things well are also those who have sense of realizing potential and improvement in self and behavior over time.

The finding is supported by Erikson's Ego Integrity (cited in Schultz \& Schultz, 2013) [23] which implies that good mental health brings about sense of fulfillment and satisfaction realizing self as growing and expanding and is open to new experiences.

Furthermore, the result of Gamma to test for relationship between depression and personal growth did not yield significant result (Gamma $=0.292 ; \mathrm{p}=0.084)$. This means that mental health in terms of depression does not have a bearing on the personal growth and development of the older people.

\section{Specific Component of Mental Health and Psychological Well-being in terms of Positive Relations of the Older People}

The statistical data between mental health and positive relation with others show that findings in all categories of mental condition in terms of somatic complaints (Gamma $=0.005 ; \mathrm{p}=0.967)$, anxiety and insomnia (Gamma $=0.242 ; \mathrm{p}=0.056)$, social dysfunction $(\mathrm{Gamma}=0.202 ; \mathrm{p}=0.177)$, and depression $(\mathrm{Gamma}=0.183 ; \mathrm{p}=0.327)$ are not significantly correlated with psychological well-being in terms of positive relation with others. This implies that mental health condition of the older people has no influence on their relationships with others.

\section{Table 4. Correlation between Specific Component of Mental Health and Positive Relations with Others}

\begin{tabular}{|l|l|l|l|}
\hline \multirow{2}{*}{$\begin{array}{l}\text { Specific Component of Mental } \\
\text { Health }\end{array}$} & \multicolumn{3}{|c|}{ Positive Relation With Others } \\
\cline { 2 - 4 } Somatic & Gamma & p-value & Decision Rule \\
\hline Anxiety and Insomnia & 0.005 & 0.967 & Not Significant \\
\hline Social Dysfunction & 0.242 & 0.056 & Not Significant \\
\hline Depression & 0.202 & 0.177 & Not Significant \\
\hline
\end{tabular}

In contrast, researchers at the Economic and Social Research Council (2013) [24] have examined how social networks have a positive psychological impact. Results showed that social relationships do contribute to better health and increased well-being.

The above finding is in contrast with the proposition in the Disengagement theory by Cumming and Henry (1961 in Miller, 2009) [25], that disengagement is adaptive, which allow the individuals to retain meaningful engagement such as family relationships and with other members of the society. Through these, older people find a sense of meaning in later life. However, in this case, it would seem that good mental condition does not essentially equate better relations with others.

\section{Specific Component of Mental Health and Psychological Well-being in terms of Purpose in Life}

The statistical data between mental health and purpose in life reveal a moderate and positive significant relationships between two variables (Gamma $=0.543 ; \mathrm{p}=0.000$ ). The null hypothesis stating that there is no significant relationship between somatic complaints and purpose in life is rejected. This indicates that mental condition in terms of somatic complaints influences their purpose in life. This further means that those respondents who does not have feeling of tightness and who are not ill are those who have high sense of meaning in life.

This is in agreement with Erickson's Ego Integrity (cited in Schultz \& Schultz, 2013) [23] which the older people are trying to find a sense of meaning in their lives that will 
help them face the inevitability of death. Thus, a high sense of integrity is related to a high sense of psychological well-being.

Table 5. Correlation between Specific Component of Mental Health and Purpose in Life

\begin{tabular}{|l|l|l|l|}
\hline \multirow{2}{*}{$\begin{array}{l}\text { Specific Component of } \\
\text { Mental Health }\end{array}$} & \multicolumn{3}{|c|}{ Purpose in Life } \\
\hline Somatic & Gamma & p-value & Decision Rule \\
\hline Anxiety and Insomnia & 0.543 & 0.000 & Significant \\
\hline Social Dysfunction & 0.488 & 0.001 & Significant \\
\hline Depression & 0.638 & 0.000 & Significant \\
\hline
\end{tabular}

As to anxiety and insomnia and purpose in life, figures suggest a significant relationship is noted as evidenced by Gamma value of $0.488(\mathrm{p}=0.001)$. This means that those respondents who are not anxious and had no difficulty sleeping are those who have high goals in life and have sense of direction.

Further, the Gamma value of $0.638(\mathrm{p}=0.000)$ is significantly correlated between social dysfunction and purpose in life. This result indicates that social functioning of the older people influences purpose in life. This signifies that those respondents who enjoy day-today activities and making plans for the future have high sense of meaning in life. No significant relationship found on depression and purpose in life $(\mathrm{Gamma}=0.248$; $\mathrm{p}=0.207$ ). This means that respondent's mental condition in terms of depression has no influence on their purpose in life. In contrast, depression can result to lack of purpose in life. Stereotypes of older people can affect their views of their own aging, which in turn can weaken their purpose in life (Hedberg, 2010) [26].

\section{Specific Component of Mental Health and Psychological Well-being in terms of Purpose in Life}

The statistical data between mental health and self-acceptance reveal the relationship between somatic complaints and self-acceptance. The Gamma value of 0.454 ( $\mathrm{p}=0.000)$ shows a significant relationship between two variables. The null hypothesis, therefore, that the mental health in terms of somatic complaints is not significantly correlated with self-acceptance of older people is rejected. The positive correlation between the two variables indicated that the good mental they have, the more they are confident and have better positive attitude toward the self. Similarly, Garcia, Al-Nima, and Kjell (2014) [20] found that good mental condition was significantly predicted by self-acceptance.

\section{Table 6. Correlation between Specific Component of Mental Health and Self- Acceptance}

\begin{tabular}{|l|l|l|l|}
\hline \multirow{2}{*}{$\begin{array}{l}\text { Specific Component of } \\
\text { Mental Health }\end{array}$} & \multicolumn{3}{|c|}{ Self-Acceptance } \\
\hline Somatic & Gamma & p-value & Decision Rule \\
\hline Anxiety and Insomnia & 0.454 & 0.000 & Significant \\
\hline Social Dysfunction & 0.288 & 0.006 & Significant \\
\hline Depression & 0.304 & 0.013 & Significant \\
\hline
\end{tabular}

In terms of anxiety and insomnia, significant relationship was found between mental health in terms of anxiety and insomnia and self-acceptance as evidenced by the Gamma value of 0.288 at $p=0.006$. This finding shows the rejection of the null hypothesis that the relationships between these variables are not significantly correlated. This signifies that 
those older people who have no difficulty in staying asleep and those with no feeling of nervousness possessed a positive attitude toward the self.

In social dysfunction, the figures show that there is a significant relationship existed between social dysfunction and self-acceptance. The Gamma value of $0.304(p=0.013)$ showed a significant correlation between two variables. This indicates that those older people who are enjoying day-to-day activities and capable of making decisions about life are more likely to have positive attitude toward the self. Social function was shown to be a better predictor well-being.

In terms of depression, the Gamma value of $0.234(\mathrm{p}=0.126)$ is not statistically significant at .05 level. The null hypothesis which states that there is no significant relationship between mental condition in terms of depression and self-acceptance is accepted. It can be deduced that the mental condition of the older people does not influence their attitude toward self. Further, regardless whether the respondents have either good or poor condition, their self-acceptance is the same.

\section{Correlation between Overall Mental Health and Overall Psychological Well-Being}

The overall statistical data between mental health and psychological well-being reveal a Gamma value of 0.267 with a significant value of 0.030 is found to be statistically significant at .05 level. This means that the null hypothesis which states that there is no significant relationship between mental health and psychological well-being is rejected. This means that the mental health of older people influences their psychological wellbeing. The good mental condition they have, the better is their psychological well-being.

\section{Table 7. Correlation between Overall Mental Health and Overall Psychological Well-Being}

\begin{tabular}{|c|c|c|c|}
\hline \multirow{3}{*}{$\begin{array}{l}\text { Overall Mental } \\
\text { Health }\end{array}$} & \multicolumn{3}{|c|}{ Overall Psychological Well-Being } \\
\hline & Gamma & $\mathrm{p}$-value & Decision Rule \\
\hline & 0.267 & 0.030 & Significant \\
\hline
\end{tabular}

Based on the focus group discussion, the following statements confirmed the relationship between good mental health and better psychological well-being.

"Positibo man ang akon panan-awan sa pangabuhi kay positibo man ang akon panumduman" (I have positive outlook in life because I think positively).

"Kada adlaw importante guid nga maayu ang imo panumduman para makaobra sang insakto" (It is important to think positively in order to work better).

"Ang maayu nga panumduman naga resulta sa maayu man nga panan-awan sa pangabuhi" (A good thinking may result to better outlook in life).

Research that has examined the influence that psychological resources have on wellbeing finds that they can have an intervening effect. They can increase the possibility of positive changes in health behaviors and well-being (Wells and Kendig, cited in Cattan, 2004) [27] or they can limit the potential negative influences on well-being of risk factors associated with aging. In the latter study, a representative sample of 420 people aged 70 and above was interviewed in North Wales. The impact of a number of factors on the person's life satisfaction were examined, and it emerged that physical health limitations, loneliness, housing difficulties and being widowed or divorced were related to lower levels of life satisfaction. However, when the person's sense of environmental mastery (measured on a nine-item scale developed by Ryff, 1989) [28] was included in the predictive model, this mitigated the effects of both physical health limitations and housing 
difficulties, and to a lesser extent, of loneliness. In other words, having a strong sense of environmental mastery reduced the impact of the difficult circumstances the older person was experiencing.

Mastery has been found to improve mental health and functioning (Badger, as cited by Cattan, 2004) [27]. Increases in mental health and life satisfaction scores were found to be associated with respondents who had higher internal locus of control (Landau and Liwin, as cited by Cattan, 2004) [27].

\section{Conclusions}

Mental health has an effect on the psychological well-being of the older people. Those older people who have good mental health are more likely to have a good sense of autonomous well-being, greater personal growth and higher sense of meaning in life, better control of the environment, more confident, and positive attitude toward self. Furthermore, the more they are involved with activities, the more likely they are satisfied with their lives. On the other hand, however, good mental health does not essentially equate better relations with others. Recommendations include strategies to improve promotion of mental health and social relations of the older people.

\section{Conflict of Interests}

The author declares no conflict of interests regarding the publication of this paper.

\section{References}

[1] R. Romulo, "Seniority of seniors in not infirmity of the aged". The Philippine Star. Available from http://www.philstar.com, (2015).

[2] World Health Organization, "Mental health: a state of well-being". Available from http://www.who.int/features/factfiles/mental_health/en/ (2014).

[3] World Health Organization, "Mental health: strengthening our response". Available from http://www.who.int/mediacentre/factsheets/fs220/en/ (2016).

[4] M. Friedman, L. Furst and K. Williams, "Physical and mental health nexus", Today's Geriatric Medicine, vol. 3, no. 4, (2010), pp. 16.

[5] World Health Organization, "Mental health and older adults". Available from http://www.who.int/ mediacentre/factsheets/fs381/en/, (2014).

[6] S. Parkar, "Elderly mental health: needs", Mens Sana Monogr, doi: 10.4103/0973-1229.153311, vol. 13, no. 1, (2015), pp. 91-99.

[7] T. Seifert, "The Ryff scales of psychological well-being", Retrieved from http://www.liberalarts.wabash.edu, (2005).

[8] T. Ordonez, T. Lima-Silva and M. Cachioni, "Subjective and psychological well-being of students of a university of the third age. Benefits of continuing education for psychological adjustment in the elderly", Dement Neuropsychol, vol. 5, no. 3, (2011), pp. 216-225.

[9] M. Luhmann, W. Hofmann, M. Eid and R. E. Lucas, "Subjective well-being and adaptation to life events: a meta-analysis", Journal of Pers Soc Psychol, doi: 10.1037/a0025948, vol. 102, no. 3, (2012), pp. 592-615.

[10] C. D. Ryff, "Psychological well-being in adult life", Current Directions in Psychological Science, doi: 10.1111/1467-8721.ep10772395, vol. 4, no. 4, (1995), pp. 99-104.

[11] F. P. David, "Understanding and doing research: a handbook for beginners", Iloilo City, Philippines: Panorama Printing Press, (2005).

[12] D. Goldberg and P. Williams, "A user's guide to the general health questionnaire", London: GL Assessment Limited, (2006).

[13] M. Taloyan, J. Sundquist and A. Al-Windi, "The impact of ethnicity and self-reported health on psychological well-being: a comparative study of Kurdish and Swedish-born people", Nord J Psychiatry, doi: 10.1080/08039480801984263, vol. 62, no. 5, (2008), pp. 392-328.

[14] B. Roothman, D. Kirsten and M. Wissing, "Gender differences in aspects of psychological well-being", South African Journal of Psychology, vol. 33, no. 4, (2003), pp. 212-218.

[15] N. A. Hamilton, C. A. Nelson, N. Stevens and H. Kitzman, "Sleep and psychological well-being", Soc Indic Res, doi: 10.1007/s11205-006-9030-1, vol. 82, no. 147, (2007).

[16] F. Mousavi, A. A. Tavabi, E. Iran-Pour, R. Tabatabaei and B. Golestan, "Prevalence and associated factors of insomnia syndrome in the elderly residing in Kahrizak Nursing Home, Tehran, Iran. Iran Journal of Public Health, vol. 41, no. 1, (2012), pp. 96-106. 
[17] R. D. Dhara and Y. A. Jogsan, "Depression and Psychological Well-being in Old Age", Journal of Psychology and Psychotherapy, doi: 10.4172/21610487.1000117, vol. 3, (2013), no. 117.

[18] N. Balkir, E. A. Arens and S. Barnow, "Exploring the relevance of autonomy and relatedness for mental health in healthy and depressed women from two different cultures: when does culture matter?", International Journal of Soc Psychiatry, doi: 10.1177/0020764012441428, vol. 59, no. 5, (2013), pp. 482-92.

[19] A. T. Beekman, B. W. Pennix, D. J. Deeg, E. de Beurs, S. W. Geerling and W. van Tilburg, "The impact of depression on the well-being, disability, and use of services in older adults: a longitudinal perspective", Acta Psychiatr Scand, vol. 105, no. 1, (2002), pp. 20-7.

[20] D. Garcia, A. Al-Nima and O. Kjell, "The affective profiles, psychological well-being, and harmony: environmental mastery and self-acceptance predict the sense of a harmonious life", Available from: https: //peerj.com/articles/259/, (2014).

[21] T. Knight, T. E. Davison, M. P. McCabe and D. Mellor, "Environmental mastery and depression in older adults in residential care", Aging and Society, doi: 10.1017/S014486X1000142X, vol. 31, no. 5, (2011), pp. 870-884.

[22] T. Touchy and K. Jett, "Ebersole and Hess' Gerontological Nursing Healthy Aging”, $3^{\text {rd }}$ Edition. MosbyElsevier: USA, (2010).

[23] D. Schultz and S. Schultz, "Theories of Personality", $8^{\text {th }}$ Edition, Wadsworth: Cengage Learning, (2013).

[24] Economic and Social Research Council, "Mental health and social relationships". Available from www.esrc.ac.uk, (2013)

[25] C. Miller, "Nursing for Wellness in Older Adults", $5^{\text {th }}$ Edition. PA, USA: Lippincott Williams and Wilkins, (2009).

[26] P. Hedberg, "Purpose in life among very old people", Doctoral dissertation, Umeå University, Umeå, Sweden, Available from http://umu.diva-portal.org/, (2010).

[27] M. Cattan, "Mental Health and Well-being in Later Life", $1^{\text {st }}$ Edition, England: Open University Press (2009).

[28] C. D. Ryff, "In the eye of the beholder: views of psychological well-being among middle- aged and older adults", Psychology and Aging, vol. 4, (1989), pp. 195-210.

\section{Author}

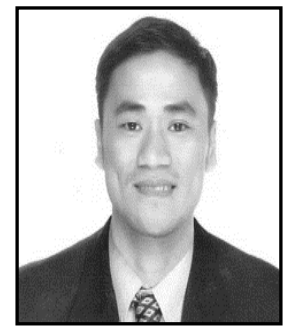

Dr. Perry Paul J. Espinosa is a Professor of Nursing in Woosong College, Daejeon, Republic of Korea. He has extensive nursing undergraduate and graduate teaching experiences. He has developed and taught advanced qualitative research inquiry in and has mentored Masters and PhD students and a panel member for various thesis and projects. 